\title{
Next-Generation Sequencing to Detect Deletion of RB1 and ERBB4 Genes in Chromophobe Renal Cell Carcinoma
}

\section{A Potential Role in Distinguishing Chromophobe Renal Cell Carcinoma from Renal Oncocytoma}

Qingqing Liu, ${ }^{*}$ Kristine M. Cornejo, ${ }^{\dagger}$ Liang Cheng, ${ }^{\ddagger}$ Lloyd Hutchinson, ${ }^{\dagger}$ Mingsheng Wang ${ }^{\ddagger}$ Shaobo Zhang, ${ }^{\ddagger}$ Keith Tomaszewicz, Ediz F. Cosar, ${ }^{\dagger}$ Bruce A. Woda, ${ }^{\dagger}$ and Zhong Jiang ${ }^{\dagger}$

From the Department of Pathology, * Icahn School of Medicine at Mount Sinai, New York, New York; the Department of Pathology, ${ }^{\dagger}$ University of Massachusetts Medical School, Worcester, Massachusetts; and the Department of Pathology, ${ }^{\ddagger}$ Indiana University School of Medicine, Indianapolis, Indiana

Accepted for publication

December 5, 2017.

Address correspondence to Zhong Jiang, M.D., Department of Pathology, University of Massachusetts Medical School, One Innovation Dr, Biotech 3, Worcester, MA 01605. E-mail: jiangz@ummhc.org.

\begin{abstract}
Overlapping morphologic, immunohistochemical, and ultrastructural features make it difficult to diagnose chromophobe renal cell carcinoma (ChRCC) and renal oncocytoma (RO). Because ChRCC is a malignant tumor, whereas RO is a tumor with benign behavior, it is important to distinguish these two entities. We aimed to identify genetic markers that distinguish ChRCC from RO by using next-generation sequencing (NGS). NGS for hotspot mutations or gene copy number changes was performed on 12 renal neoplasms, including seven ChRCC and five RO cases. Matched normal tissues from the same patients were used to exclude germline variants. Rare hotspot mutations were found in cancer-critical genes (TP53 and PIK3CA) in ChRCC but not R0. The NGS gene copy number analysis revealed multiple abnormalities. The two most common deletions were tumor-suppressor genes RB1 and ERBB4 in ChRCC but not RO. Fluorescence in situ hybridization was performed on 65 cases (ChRCC, $n=33 ; \mathrm{RO}, n=32$ ) to verify hemizygous deletion of $R B 1(17 / 33,52 \%$ ) or ERBB4 $(11 / 33,33 \%)$ in ChRCC, but not in R0 (0/32, 0\%). In total, ChRCCs $(23 / 33,70 \%)$ carry either a hemizygous deletion of $R B 1$ or $E R B B 4$. The combined use of $R B 1$ and $E R B B 4$ fluorescence in situ hybridization to detect deletion of these genes may offer a highly sensitive and specific assay to distinguish ChRCC from RO. (Am J Pathol 2018, 188: 846-852; https://doi.org/10.1016/j.ajpath.2017.12.003)
\end{abstract}

Both chromophobe renal cell carcinoma (ChRCC) and renal oncocytoma (RO) are tumors that originate from the intercalated cells of the collecting system. Microscopically, ChRCC contains polygonal cells with cytoplasm ranging from pale to eosinophilic and displays nested, alveolar, or sheet-like growth patterns. RO shares many histologic features with ChRCC. Histologically, RO is composed of uniform round/polygonal tumor cells with abundant eosinophilic, granular cytoplasm, and small round nuclei, arranged in nests, solid, and/or tubular patterns. ${ }^{1,2}$ Atypical features have been reported in RO, despite the benign behavior associated with this tumor, and include chromophobe histology, significant nuclear atypia (bizarre cells with high nuclear/cytoplasm ratio and hyperchromatic nuclei), invasion into the renal sinus and perirenal fat and vessels, as well as rare mitoses and focal areas of necrosis. ${ }^{1}$ These morphologic features may generate diagnostic dilemmas. In routine clinical practice, special and immunohistochemical stains are commonly used to distinguish ChRCC from RO, and include

Supported by the Department of Pathology, University of Massachusetts Medical School, and the Department of Pathology, Indiana University School of Medicine.

Disclosures: None declared. 
Hale's colloidal iron and cytokeratin $7 .{ }^{3}$ These markers are usually diffusely and are strongly positive in ChRCC, whereas they are typically negative or show scattered positivity in RO. However, subsets of ChRCC are reported to be negative for these markers, whereas a variable degree of positive staining has also been documented in RO. Therefore, the results of immunohistochemical studies are not always conclusive. $^{3-6}$

It is well established that ChRCC and RO have different patterns of chromosomal anomalies, including copy number gains and losses at distinct chromosomal loci. ${ }^{7-10}$ Specifically, ChRCC are frequently associated with gains in chromosomes 4, 7, 11,12,14q, and 18q, and losses in chromosomes $\mathrm{Y}, 1,2,6,10,13,17$, and 21 . Among the latter, losses of chromosomes 2, 6, 10, and 17 seem to be specific for ChRCC. ${ }^{9,11}$ RO occasionally exhibits losses of chromosomes 1 and $\mathrm{Y}$ and/or balanced translocation of the 11q13 breakpoint region. ${ }^{12,13}$ Common losses of chromosomes in both ChRCC and RO suggest that there is a close relationship between ChRCC and RO. ${ }^{14-16}$ The chromosomal anomalies are usually identified by conventional cytogenetic analysis, together with other approaches, such as comparative genomic hybridization and restriction fragment length polymorphism analysis. ${ }^{17-19}$ Herein, next-generation sequencing (NGS) was used to distinguish these two entities from each other and fluorescence in situ hybridization (FISH) was used to confirm these findings.

\section{Materials and Methods}

Sixty-five cases (ChRCC, $n=33$; RO, $n=32$ ) were retrieved from the surgical pathology files of the Departments of Pathology at the University of Massachusetts Medical School (Worcester, MA) and at the Indiana University School of Medicine (Indianapolis, IN). Relevant clinical records were reviewed for clinical presentation, tumor size, stage, treatment, and clinical outcome. Representative hematoxylin and eosin-stained sections were reviewed to confirm the diagnoses by two genitourinary pathologists (Q.L. and Z.J.). At the University of Massachusetts Medical School, ChRCC cases $(n=11)$ were selected between 1995 and 2010 and were composed of three female and eight male patients, with ages ranging from 28 to 75 years (mean age, 50.8 years) with all localized tumors (T1, $n=1$; T2, $n=5$; T3, $n=5$ ); RO cases $(n=10)$ were selected between 1999 and 2009 and included two female and eight male patients, with ages ranging between 41 and 84 years (mean age, 64.7 years). At the Indiana University School of Medicine, ChRCC cases $(n=22)$ were selected between 2015 and 2017 and were composed of 12 female and 10 male patients, with ages ranging from 31 to 81 years (mean age, 58.3 years), with all localized tumors (T1, $n=12$; T3, $n=10$ ); RO cases $(n=22)$ were selected between 2012 and 2017 and included six female and 16 male patients, with ages ranging between 41 and 87 years (mean age, 66.1 years).
Targeted Mutational Sequencing and Copy Number Variation Analysis by NGS

Tumor and matched normal tissue from the same patient was identified on a hematoxylin and eosin-stained slide, then macrodissected from sequential sections, typically three to five slides of formalin-fixed, paraffin-embedded tissue ( $7 \mu \mathrm{m}$ thick). DNA was purified using the QIAamp DNA FFPE Tissue kit (Qiagen, Valencia, CA), then quantified by spectrometry (NanoDrop 1000 DNA/RNA Calculator; Thermo Scientific, Wilmington, DE) and fluorometry (Qubit DNA High-Sensitivity Assay Kit; Thermo Scientific). Pooling with short known nucleotides known as barcodes could be adapted to the amplicons with the IonXpress Barcode Kit (Life Technologies, Carlsbad, CA) if multiplexing of samples was desired.

Next-generation mutation sequencing and gene copy number analysis were performed as previously described. ${ }^{20}$ Briefly, AmpliSeq Cancer Hotspot Panel v2 libraries were generated from genomic DNA (10 ng) using the Ion AmpliSeq Library Kit 2.0 (Thermo Scientific) and quantified using the Ion Library Quantification KIT (Thermo Scientific) on a CFX96 Touch Real-Time PCR Detection System (Bio-Rad Laboratories, Hercules, CA). Genes in this panel are AKT1, ALK, APC, ATM, ABL1, BRAF, FGFRl, GNAS, IDH1, FGFR2, KRAS, NRAS, PIK3CA, MET, RET, EGFR, JAK2, MPL, PDGFRA, PTEN, TP53, FGFR3, FLT3, KIT, ERBB2, EZH2, IDH2, GNA11, GNAQ, HNF1A, HRAS, RB1, CDH1, SMAD4, STK11, SRC, SMARCB1, VHL, MLH1, CTNNB1, KDR, FBXW7, CSF1R, NPM1, SMO, ERBB4, CDKN2A, NOTCH1, JAK3, and PTPN11. Libraries were diluted and combined together, and emulsion PCR was performed on the One Touch 2 System (Thermo Scientific) using the OT200 template kit to amplify library DNA onto IonSphere particles. Enrichment of IonSphere particles with clonally amplified sequencing template relied on the OneTouch ES System (Thermo Scientific). Sequencing was performed on an Ion Torrent PGM (IC200 Sequencing Kit, Ion 318 chip; Thermo Fischer), which generates a FASTQ from the raw data file.

FASTQ files were analyzed using three pipelines to identify somatic mutations: Variant Caller version 4 (Thermo Scientific), Ion Reporter version 5 (Thermo Scientific), and NextGENe version 2.4 (Softgenetics, State College, PA). Initial criteria used to call sequence variants relied on detection by multiple pipelines with amplicon coverage of $>500 \times$, a variant frequency $>3 \%$ with at least 20 reads in a wild-type background, and absence of the same variant in matched normal tissue. After review, variants were confirmed as somatic mutations in the Catalogue of Somatic Mutations in Cancer database ${ }^{21}$ or ruled out as a known germline single-nucleotide polymorphisms with the Single Nucleotide Polymorphism Database. ${ }^{2}$

Copy number variants (CNVs) were identified using Ion Reporter and NextGENe. Specimens were excluded from copy number analysis for the following reasons: i) low 
sequencing coverage $(n=4,<500 \times /$ amplicon $)$, ii) poor-quality DNA, producing DNA sequencing artifacts ( $n=2,>50$ low-level variants with $<2 \%$ allele frequency), or iii) an estimated tumor percentage of $<50 \%(n=2)$. CNV detection was achieved by comparison of tumor amplicon coverage with matched normal tissue (pairedsample workflow) or comparison to a group average of 10 normal control tissues (multiple control workflow). The analysis incorporated the tumor percentage estimated by the pathologist to determine copy number. Any gene with a single amplicon probe was excluded from the analysis. Results from multiple probes were combined to generate a single gene gain/deletion score. Copy numbers $>3.3$ were defined as a gain, and copy numbers $<1.2$ were defined as a loss. CNV calls made by both software packages were tabulated and reported both by gene and chromosome region. CNV changes present in $>60 \%$ of ChRCC specimens were then confirmed by FISH.

For NextGENe, a coverage ratio (sample divided by sample plus control) is the basis for CNV detection. Coverage is converted to a normalized read count value to account for differences in coverage from sample to sample. A $\beta$-binomial model is fit to the coverage ratio to model the amount of noise (dispersion). The likelihood a copy number variant is present is calculated from the coverage ratio and dispersion value and can factor estimated tumor purity and expected CNV percentage. A hidden Markov model makes the CNV classification of duplication, normal, or deletion with accompanying Phred-scaled probability scores.

The Ion Reporter predicts the copy number or ploidy state $(0,1,2,3$, etc) of the tumor by comparing normalized read coverage (after correction for GC bias) to a baseline constructed from control sample(s) with known ploidy. A statistical model adjusts for regions with low read coverage and significant variation, then calculates the likelihood a gene belongs to an alternate ploidy state. A hidden Markov model framework determines the optimal path through the ploidy state to maximize the total ploidy state likelihoods when state transition penalties are considered. A medium setting using medium transition penalties was used to enable robust CNV detection with few false-positive calls. Confidence (log ratio of called ploidy versus expected ploidy state likelihoods) and precision (log ratio of assigned ploidy versus next-closest ploidy state likelihoods) scores accompany the copy number predictions.

\section{Fluorescence in Situ Hybridization}

FISH analysis was performed as described previously. ${ }^{23-28}$ Briefly, multiple sections ( $4 \mu \mathrm{m}$ thick) were obtained from formalin-fixed, paraffin-embedded tissue blocks containing neoplastic tissue. A hematoxylin and eosin-stained slide from each block was examined to identify areas of neoplastic tissue for FISH analysis. The slides were deparaffinized with two washes of xylene, 15 minutes each, and subsequently washed twice with absolute ethanol,
10 minutes each, and then air dried in a fume hood. Next, the slides were treated with $0.1 \mathrm{mmol} / \mathrm{L}$ citric acid $(\mathrm{pH} 6.0)$ (Zymed, South San Francisco, CA) at $95^{\circ} \mathrm{C}$ for 10 minutes, rinsed in distilled water for 3 minutes, followed by a wash of $2 \times$ standard saline citrate for 5 minutes. Digestion of nuclear proteins was performed by applying $0.4 \mathrm{~mL}$ of pepsin $(5 \mathrm{mg} / \mathrm{mL}$ in $0.01 \mathrm{~N} \mathrm{HCl} / 0.9 \% \mathrm{NaCl}$; Sigma, St. Louis, MO) at $37^{\circ} \mathrm{C}$ for 40 minutes. The slides were rinsed with distilled water for 3 minutes, washed with $2 \times$ standard saline citrate for 5 minutes, and air dried.

FISH used a cocktail of dual-color DNA probes from Empire Genomics (Buffalo, NY) that targeted RB1-Orange (MAC clone RP11-893E5) and 13q11-Green (RP11-408E5). The second cocktail of dual-color probes consisted of ERBB4-Green (Empire Genomics) and CEP2-Orange (Abbott Molecular, Lake Bluff, IL). Probes were diluted at 1:25 with tDenHyb 2 (Insitus, Albuquerque, NM). Diluted probe $(5 \mu \mathrm{L})$ was applied to each slide in reduced light conditions. The slides were then covered with a $22 \times 22-\mathrm{mm}$ coverslip and sealed with rubber cement. Denaturation was achieved by incubating the slides at $83^{\circ} \mathrm{C}$ for 12 minutes in a humidified box, followed by hybridization at $37^{\circ} \mathrm{C}$ overnight.

The coverslips were removed, and the slides were washed twice with $0.1 \times$ standard saline citrate $/ 1.5 \mathrm{mmol} / \mathrm{L}$ urea at $45^{\circ} \mathrm{C}$ (20 minutes for each), followed by a wash with $2 \times$ standard saline citrate for 20 minutes, and with $2 \times$ standard saline citrate/ $0.1 \%$ NP-40 for 10 minutes at $45^{\circ} \mathrm{C}$. The slides were further washed with room temperature $2 \times$ standard saline citrate for 5 minutes. The slides were air dried and counterstained with $10 \mathrm{~mL}$ DAPI (Insitus), covered with coverslips, and sealed with nail polish.

\section{FISH Evaluation}

The slides were examined using a Zeiss Axioplan 2 microscope (ZEISS, Göttingen, Germany) with the following filters (Chroma, Brattleboro, VT): SP-100 for DAPI, fluorescein isothiocyanate MF-101 for Spectrum Green, and Gold 31003 for Spectrum Orange. The hybridized slides were analyzed and documented using a MetaSystem system (Belmont, MA) under a $100 \times$ oil objective. Four sequential focus stacks with $0.3-\mu \mathrm{m}$ intervals were acquired and integrated into a single image to reduce thickness-related artifacts. Signals from each color channel (probe) were counted under pseudocolor, with computerized translation of each color channel into blue, green, and red. A minimum of 100 nonoverlapping cancer cells were evaluated for each case. Slides were counted only if $>90 \%$ of cells demonstrated satisfactory signal quality. ${ }^{23-28}$

The deletion threshold for $R B 1$ and ERBB4 copy number was based on previous literature, including studies of chromosome $1 \mathrm{p} / 19 \mathrm{q}$ deletions in oligodendrogliomas. ${ }^{29-32}$ Homozygous deletions of $R B 1$ or ERBB4 were defined as the absence of both gene-specific signals with intact control signals in $\geq 50 \%$ of cells. Hemizygous deletions were 
Table 1 Next-Generation Sequencing Data for RO and ChRCC

\begin{tabular}{|c|c|c|c|c|c|c|c|c|c|c|c|c|c|c|c|c|c|}
\hline \multirow[b]{2}{*}{ Chromosome } & \multirow[b]{2}{*}{ Gene } & \multicolumn{7}{|l|}{ RO } & \multicolumn{9}{|l|}{ ChRCC } \\
\hline & & $\begin{array}{l}\% \text { with } \\
\text { loss }\end{array}$ & $\begin{array}{l}\% \text { with } \\
\text { gain }\end{array}$ & 1 & 2 & 3 & 4 & 5 & 6 & 7 & 8 & 9 & 10 & 11 & 12 & $\begin{array}{l}\% \text { with } \\
\text { loss }\end{array}$ & $\begin{array}{l}\% \text { with } \\
\text { gain }\end{array}$ \\
\hline 2 & $A L K$ & 0 & 20 & & & & & & $(-)$ & & $(-)$ & & & $(-)$ & & 38 & 0 \\
\hline 2 & ERBB 4 & 0 & 0 & & & & & & $(-)$ & & $(-)$ & & $(-)$ & $(-)$ & & 63 & 0 \\
\hline 3 & $V H L$ & 0 & 0 & & & & & & & & & & & & & 0 & 0 \\
\hline 4 & PDGFRA & 0 & 0 & & & & & & & & & & & & & 0 & 0 \\
\hline 4 & KIT & 0 & 0 & & & & & & & & & & & & & 0 & 0 \\
\hline 4 & $K D R$ & 0 & 0 & & & & & & & & & & & & & 0 & 0 \\
\hline 4 & FBXW7 & 0 & 0 & & & & & & & & $(-)$ & & & & & 13 & 0 \\
\hline 5 & $A P C$ & 0 & 0 & & & & & & & & & & & & & 13 & 0 \\
\hline 7 & $B R A F$ & 0 & 0 & & & & & & & & & & $(-)$ & $(-)$ & & 38 & 0 \\
\hline 8 & FGFR1 & 0 & 0 & & & & & & & & & & & & & 0 & 0 \\
\hline 9 & $C D K N 2 A$ & 40 & 20 & $(-)$ & $(-)$ & & & $(+)$ & & $(-)$ & & $(-)$ & & & & 25 & 0 \\
\hline 9 & $A B L 1$ & 0 & 0 & & & & & & & & & & & $(+)$ & & 0 & 25 \\
\hline 9 & NOTCH1 & 40 & 20 & $(-)$ & $(-)$ & & & $(+)$ & & $(-)$ & & & $(+)$ & $(+)$ & & 13 & 38 \\
\hline 10 & RET & 20 & 0 & & $(-)$ & & & & $(-)$ & $(-)$ & & & & & & 25 & 0 \\
\hline 10 & PTEN & 0 & 0 & & & & & & $(-)$ & & & & & $(-)$ & & 38 & 0 \\
\hline 10 & FGFR2 & 0 & 0 & & & & & & $(-)$ & & & & & & & 13 & 0 \\
\hline 11 & HRAS & 0 & 20 & & & & & $(+)$ & $(-)$ & & & & $(+)$ & $(+)$ & & 13 & 38 \\
\hline 11 & ATM & 0 & 0 & & & & & & $(-)$ & & & & & & & 13 & 0 \\
\hline 12 & KRAS & 0 & 0 & & & & & & & & & & & & & 13 & 0 \\
\hline 17 & ERBB2 & 0 & 0 & & & & & & $(-)$ & $(-)$ & $(-)$ & & $(+)$ & & & 38 & 13 \\
\hline 18 & SMAD4 & 0 & 0 & & & & & & & & & & & & & 0 & 0 \\
\hline 19 & STK11 & 0 & 0 & & & & & & & $(-)$ & & & $(+)$ & $(+)$ & & 13 & 38 \\
\hline 19 & JAK3 & 0 & 0 & & & & & & & & & & $(+)$ & $(+)$ & & 0 & 38 \\
\hline 20 & GNAS & 0 & 0 & & & & & & & & & & & $(+)$ & & 0 & 13 \\
\hline 22 & SMARCB1 & 20 & 0 & & $(-)$ & & & & & & & & & & & 0 & 13 \\
\hline
\end{tabular}

Two or more cases carrying loss or gain $(\geq 29 \%)$ of total cases tested are in bold.

Loss $(-),<1.2$ gene copies; Gain $(+),>3.3$ gene copies; \%, loss or gain, percentage of gains or losses.

ChRCC, chromophobe renal cell carcinoma; RO, renal oncocytoma.

defined by the presence of only one of the gene-specific signals in $\geq 50 \%$ of nuclei. ${ }^{31,32}$

\section{Results}

Rare Hotspot Mutations in 50 0ncogenes and TumorSuppressor Genes Identified in ChRCC but Not RO

It was first examined whether ChRCC $(n=7)$ or RO $(n=5)$ carried any hotspot somatic mutations in 50 oncogenes and tumor-suppressor genes using NGS. The 50 oncogenes and tumor-suppressor genes are those most commonly involved in human cancers (Materials and Methods). Approximately 2800 Catalogue of Somatic Mutations in Cancer mutational loci in 50 genes are targeted and sequenced. These regions are described as hotspot because they are frequently mutated in human cancers. Single TP53 or PIK3CA mutations were detected in two ChRCCs at allele frequencies of $9 \%$ and $21 \%$, respectively. The tumor percentage of the TP53 mutant ChRCC was estimated to be $50 \%$, indicating the mutation is present only in a subset of tumor cells. 
Table 2 Hemizygous Deletions of RB1 and ERBB4 Genes and Their Frequency of Occurrence in RO and ChRCC by FISH Study

\begin{tabular}{lllll}
\hline & $\begin{array}{l}\text { Cases with } \\
\text { hemizygous } \\
\text { RB1 }\end{array}$ & $\begin{array}{l}\text { Cases with } \\
\text { hemizygous } \\
\text { ERBB4 }\end{array}$ & $\begin{array}{l}\text { Cases with } \\
\text { either } R B 1 \text { or }\end{array}$ & Total \\
Diagnosis & deletion & deletion & ERBB4 deletions & cases \\
\hline ChRCC & $17 / 33(52)$ & $11 / 33(33)$ & $23 / 33(70)$ & 33 \\
R0 & $0 / 32(0)$ & $0 / 32(0)$ & $0 / 32(0)$ & 32 \\
\hline
\end{tabular}

Data are given as $n$ or $n /$ total (\%).

ChRCC, chromophobe renal cell carcinoma; FISH, fluorescence in situ hybridization; R0, renal oncocytoma.

\section{Copy Number Analysis Reveals Hemizygous Deletions} of Tumor-Suppressor Genes RB1 and ERBB4 in ChRCC, Which Were Verified by FISH

It was further examined if there were any copy number variations in these 50 cancer-critical genes in ChRCC and RO genes that showed copy number gain or loss in at least $35 \%$ of ChRCC or RO (ie, not disomic). In the ChRCC subgroup, seven genes showed copy number loss and eight genes showed copy number gain, whereas the RO subgroup showed only two genes with copy number loss (Table 1 ). Both $R B 1$ and ERBB4 showed loss of copy numbers in $>60 \%$ of ChRCC, but were not deleted in RO (Table 1).

The deletions of $R B 1$ and $E R B B 4$ genes were subsequently verified by FISH, with chromosomal probes directed against $R B 1$ and $E R B B 4$. It was confirmed that there is a good correlation between the NGS and the FISH results in each specific case (Pearson correlation coefficient $=1, P<0.01$ ) (Table 1 and Supplemental Table S1). FISH studies demonstrated a hemizygous deletion of the $R B 1$ gene in 17 of 33 ChRCC cases (52\%), but not in any of $32 \mathrm{RO}$ cases $(0 \%)$ (Table 2, Figure 1, and Supplemental Table S1). Consistent with the NGS data, a hemizygous deletion of the ERBB4 gene was detected in 11 of 33 ChRCC cases by FISH (33\%), whereas none of the $32 \mathrm{RO}$ cases showed ERBB4 deletion (0\%) (Table 2, Figure 1, and Supplemental Table S1). Furthermore, there was no significant correlation between ChRCC tumor stages and $R B 1$ gene deletion (T1, 7/13, 54\%; $\mathrm{T} 2,2 / 5,40 \%$; T3, 8/15, 53\%; $P=0.31, \chi^{2}$ test). Similarly, ChRCC tumor stage did not correlate with ERBB4 gene deletion (T1, 2/13, 23\%; T2, 2/5, 40\%; and T3, 6/15, 40\%; $P=0.32, \chi^{2}$ test). Taken together, 23 of 33 ChRCC cases carried either an RBI and/or ERBB4 gene deletion (70\%) (Table 2). In contrast, none of the RO cases showed deletion of these two genes (0\%) (Table 2).

\section{Discussion}

In this study, NGS was used to detect mutations and copy number variation in ChRCC and RO. This approach showed deletion of tumor-suppressor genes $R B 1$ and $E R B B 4$ in most ChRCC cases, but not in RO cases. On the basis of these NGS results, a simple FISH assay was adopted to confirm these findings. $R B 1$ and/or ERBB4 deletions occurred in $70 \%$ of ChRCC cases but not in RO cases. Consequently, the combined use of $R B 1$ and ERBB4 deletions by FISH yielded a highly specific and sensitive diagnostic assay to differentiate these tumors. Like other FISH assays, the RBI and $E R B B 4$ probes can be applied to surgical biopsy specimens or cell blocks derived from fine-needle aspiration of renal tumors. If applied to clinical practice, the presence of $R B 1$ and ERBB4 deletion may help to exclude an $\mathrm{RO}$ and rule in a ChRCC. Nevertheless, the results of this study are based on a few cases. The diagnostic significance of the combined use of $R B 1$ and ERBB4 gene deletions as a diagnostic marker should be further examined in larger numbers of patients with ChRCC and RO.

The molecular mechanism of ChRCC tumorigenesis remains largely unclear. ChRCCs are frequently associated with large multiallelic copy number variations that include gains in chromosomes $4,7,11,12,14 \mathrm{q}$, and $18 \mathrm{q}$ and losses in
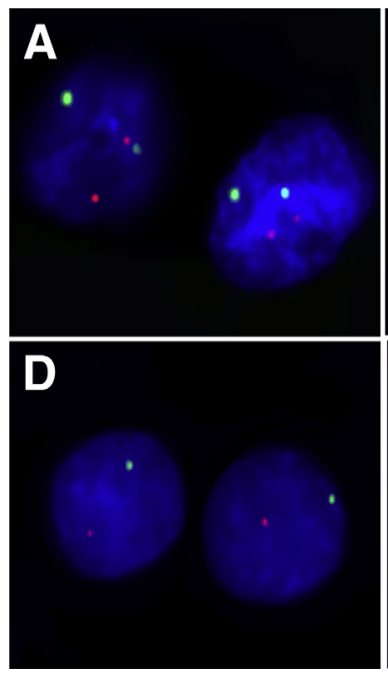
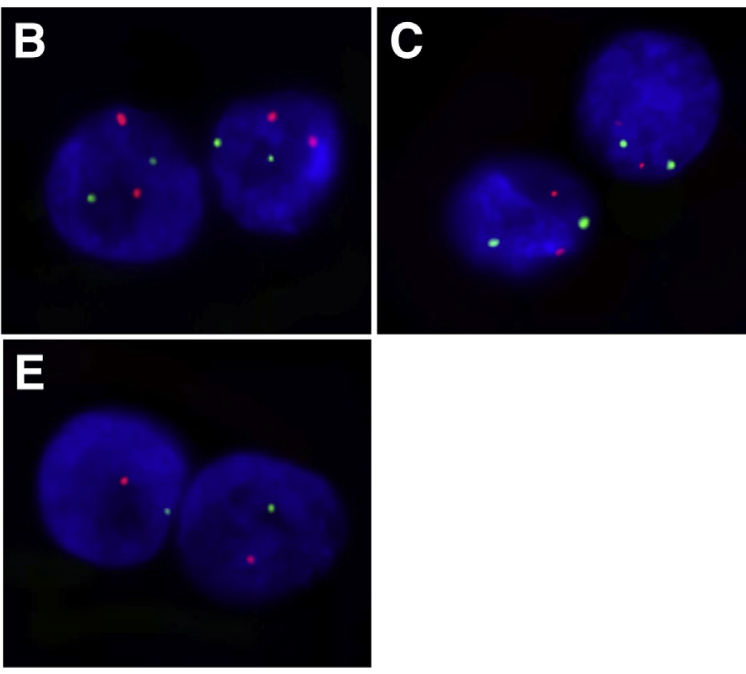

Figure 1 Fluorescence in situ hybridization analysis of RB1 and ERBB4 genes in chromophobe renal cell carcinoma (ChRCC) and renal oncocytoma (RO). A: Normal tissue, with green signals indicating chromosomal centromere regions and red signals showing the presence of disomic RB1 gene. $\mathbf{B}$ and C: Disomic RB1 genes (red; B) and disomic ERBB4 genes (green; C) in RO cells. D and E: A hemizygous deletion of $R B 1$ gene (loss of one red signal; D) and ERBB4 gene (loss of one green signal; E) in ChRCC. Original magnification, $\times 400$ (A-E). 
chromosome Y, 1, 2, 6, 10, 13, 17, and $21 .^{33}$ It has been reported that the loss of chromosomes $\mathrm{Y}, 1,2,6,10,13,17$, and 21 is nonrandom and might lead to tumor suppressor gene inactivation, promoting tumorigenesis. ${ }^{33,34}$ In the FISH assay, accompanying losses of centromere signals were observed in ChRCC cases carrying $R B 1$ or ERBB 4 deletions. These data suggest either a whole chromosomal deletion or a large partial chromosomal deletion that is composed of $R B I$ or ERBB4 and the corresponding centromere region. The NGS data favor the latter because genes present in different areas of chromosomes 2 or 13 are identified in the same ChRCC cases with centromere loss (Table 1). Deletions that span a centromere will not affect chromosomal DNA replication because an origin of replication is found every 250 kilobase of human DNA. However, the resulting acentric chromosome will most likely be lost during cell division, unless there is a selective pressure that helps to maintain the acentric chromosome in the genome. Centromere deletion has been described in naturally occurring precancer and cancer genomes, including myelodysplastic syndrome and acute myeloid leukemia. ${ }^{3 .}$

Previous reports indicate RO occasionally exhibits losses of chromosome $1 .^{12,13}$ In this study, gene amplicons targeting chromosome $1 \mathrm{did}$ not reveal obvious alterations in the RO cohort. Copy number changes in CDKN2A and $N O T C H$ on chromosome 9 were observed in RO, but these abnormalities were also found in ChRCC.

In contrast to the numerous chromosomal anomalies found in ChRCC, this tumor type is reported to have a low rate of somatic mutation. ${ }^{36}$ Similarly, only two somatic mutations were observed in 10 ChRCCs tested. Davis et $\mathrm{al}^{37}$ used mitochondrial DNA and whole-genome sequencing to show TP53 mutations and PTEN mutations in 21 and six ChRCC cases (32\% and 9\%), respectively. In this study, a TP53 mutation was identified in one ChRCC (10\%), but PTEN mutations were not observed. In agreement with previous studies, no KIT mutations were detected in either ChRCC or $\mathrm{RO}$, despite overexpression of C-kit in these two tumors. ${ }^{38-40}$

In summary, NGS demonstrated multiple gene copy abnormalities, the two most common being RBI and ERBB4 in ChRCC, but not in RO. FISH was used to confirm these gene deletions in ChRCC. The FISH assay combining $R B I$ and $E R B B 4$ probes for formalin-fixed, paraffin-embedded tissue sections offers a highly sensitive and specific genetic marker in distinguishing ChRCC from benign RO.

\section{Supplemental Data}

Supplemental material for this article can be found at https://doi.org/10.1016/j.ajpath.2017.12.003.

\section{References}

1. Trpkov K, Yilmaz A, Uzer D, Dishongh KM, Quick CM, Bismar TA, Gokden N: Renal oncocytoma revisited: a clinicopathological study of
109 cases with emphasis on problematic diagnostic features. Histopathology 2010, 57:893-906

2. Kolnikova G, Marinova P, Gal V, Meciarova I, Misanko V, Rampalova J, Jani P, Orthova S, Ondrias F, Cano M: Renal oncocytoma with invasive histopathologic features: case report. Klin Onkol 2014, 27:138-142

3. Memeo L, Jhang J, Assaad AM, McKiernan JM, Murty VV, Hibshoosh H, Tong GX, Mansukhani MM: Immunohistochemical analysis for cytokeratin 7, KIT, and PAX2: value in the differential diagnosis of chromophobe cell carcinoma. Am J Clin Pathol 2007, 127:225-229

4. Young AN, de Oliveira Salles PG, Lim SD, Cohen C, Petros JA, Marshall FF, Neish AS, Amin MB: Beta defensin-1, parvalbumin, and vimentin: a panel of diagnostic immunohistochemical markers for renal tumors derived from gene expression profiling studies using cDNA microarrays. Am J Surg Pathol 2003, 27:199-205

5. Takahashi M, Yang XJ, Sugimura J, Backdahl J, Tretiakova M, Qian CN, Gray SG, Knapp R, Anema J, Kahnoski R, Nicol D, Vogelzang NJ, Furge KA, Kanayama H, Kagawa S, Teh BT: Molecular subclassification of kidney tumors and the discovery of new diagnostic markers. Oncogene 2003, 22:6810-6818

6. Abrahams NA, MacLennan GT, Khoury JD, Ormsby AH, Tamboli P, Doglioni C, Schumacher B, Tickoo SK: Chromophobe renal cell carcinoma: a comparative study of histological, immunohistochemical and ultrastructural features using high throughput tissue microarray. Histopathology 2004, 45:593-602

7. Bugert P, Kovacs G: Molecular differential diagnosis of renal cell carcinomas by microsatellite analysis. Am J Pathol 1996, 149: 2081-2088

8. Decker HJ, Neuhaus C, Jauch A, Speicher M, Ried T, Bujard M, Brauch H, Storkel S, Stockle M, Seliger B, Huber C: Detection of a germline mutation and somatic homozygous loss of the von HippelLindau tumor-suppressor gene in a family with a de novo mutation: a combined genetic study, including cytogenetics, PCR/SSCP, FISH, and CGH. Hum Genet 1996, 97:770-776

9. Tan MH, Wong CF, Tan HL, Yang XJ, Ditlev J, Matsuda D, Khoo SK, Sugimura J, Fujioka T, Furge KA, Kort E, Giraud S, Ferlicot S, Vielh P, Amsellem-Ouazana D, Debre B, Flam T, Thiounn N, Zerbib M, Benoit G, Droupy S, Molinie V, Vieillefond A, Tan PH, Richard S, Teh BT: Genomic expression and single-nucleotide polymorphism profiling discriminates chromophobe renal cell carcinoma and oncocytoma. BMC Cancer 2010, 10:196

10. Kovacs A, Storkel S, Thoenes W, Kovacs G: Mitochondrial and chromosomal DNA alterations in human chromophobe renal cell carcinomas. J Pathol 1992, 167:273-277

11. Kovacs A, Kovacs G: Low chromosome number in chromophobe renal cell carcinomas. Genes Chromosomes Cancer 1992, 4:267-268

12. Crotty TB, Lawrence KM, Moertel CA, Bartelt DH Jr, Batts KP, Dewald GW, Farrow GM, Jenkins RB: Cytogenetic analysis of six renal oncocytomas and a chromophobe cell renal carcinoma: evidence that $-\mathrm{Y},-1$ may be a characteristic anomaly in renal oncocytomas. Cancer Genet Cytogenet 1992, 61:61-66

13. Fuzesi L, Gunawan B, Braun S, Bergmann F, Brauers A, Effert P, Mittermayer C: Cytogenetic analysis of 11 renal oncocytomas: further evidence of structural rearrangements of $11 \mathrm{q} 13$ as a characteristic chromosomal anomaly. Cancer Genet Cytogenet 1998, 107:1-6

14. Tickoo SK, Reuter VE, Amin MB, Srigley JR, Epstein JI, Min KW, Rubin MA, Ro JY: Renal oncocytosis: a morphologic study of fourteen cases. Am J Surg Pathol 1999, 23:1094-1101

15. Al-Saleem T, Cairns P, Dulaimi EA, Feder M, Testa JR, Uzzo RG: The genetics of renal oncocytosis: a possible model for neoplastic progression. Cancer Genet Cytogenet 2004, 152:23-28

16. Pavlovich CP, Walther MM, Eyler RA, Hewitt SM, Zbar B, Linehan WM, Merino MJ: Renal tumors in the Birt-Hogg-Dube syndrome. Am J Surg Pathol 2002, 26:1542-1552

17. Speicher MR, Schoell B, du Manoir S, Schrock E, Ried T, Cremer T, Storkel S, Kovacs A, Kovacs G: Specific loss of chromosomes 1, 2, 6, 
$10,13,17$, and 21 in chromophobe renal cell carcinomas revealed by comparative genomic hybridization. Am J Pathol 1994, 145:356-364

18. Junker K, Weirich G, Amin MB, Moravek P, Hindermann W, Schubert J: Genetic subtyping of renal cell carcinoma by comparative genomic hybridization. Recent Results Cancer Res 2003, 162: $169-175$

19. Schwerdtle RF, Storkel S, Neuhaus C, Brauch H, Weidt E, Brenner W, Hohenfellner R, Huber C, Decker HJ: Allelic losses at chromosomes 1p, $2 \mathrm{p}, 6 \mathrm{p}, 10 \mathrm{p}, 13 \mathrm{q}, 17 \mathrm{p}$, and $21 \mathrm{q}$ significantly correlate with the chromophobe subtype of renal cell carcinoma. Cancer Res 1996, 56:2927-2930

20. Liu Q, Tomaszewicz K, Hutchinson L, Hornick JL, Woda B, Yu H: Somatic mutations in histiocytic sarcoma identified by next generation sequencing. Virchows Arch 2016, 469:233-241

21. Forbes SA, Bindal N, Bamford S, Cole C, Kok CY, Beare D, Jia M, Shepherd R, Leung K, Menzies A, Teague JW, Campbell PJ, Stratton MR, Futreal PA: COSMIC: mining complete cancer genomes in the Catalogue of Somatic Mutations in Cancer. Nucleic Acids Res 2011, 39:D945-D950

22. Sherry ST, Ward MH, Kholodov M, Baker J, Phan L, Smigielski EM, Sirotkin K: dbSNP: the NCBI database of genetic variation. Nucleic Acids Res 2001, 29:308-311

23. Cheng L, MacLennan GT, Zhang S, Wang M, Zhou M, Tan PH, Foster S, Lopez-Beltran A, Montironi R: Evidence for polyclonal origin of multifocal clear cell renal cell carcinoma. Clin Cancer Res 2008, 14:8087-8093

24. Cheng L, Zhang S, MacLennan GT, Lopez-Beltran A, Montironi R: Molecular and cytogenetic insights into the pathogenesis, classification, differential diagnosis, and prognosis of renal epithelial neoplasms. Hum Pathol 2009, 40:10-29

25. Gobbo S, Eble JN, Maclennan GT, Grignon DJ, Shah RB, Zhang S, Martignoni G, Brunelli M, Cheng L: Renal cell carcinomas with papillary architecture and clear cell components: the utility of immunohistochemical and cytogenetical analyses in differential diagnosis. Am J Surg Pathol 2008, 32:1780-1786

26. Jones TD, Eble JN, Wang M, MacLennan GT, Delahunt B, Brunelli M, Martignoni G, Lopez-Beltran A, Bonsib SM, Ulbright TM, Zhang S, Nigro K, Cheng L: Molecular genetic evidence for the independent origin of multifocal papillary tumors in patients with papillary renal cell carcinomas. Clin Cancer Res 2005, 11:7226-7233

27. Williamson SR, Zhang S, Eble JN, Grignon DJ, Martignoni G, Brunelli M, Wang M, Gobbo S, Baldridge LA, Cheng L: Clear cell papillary renal cell carcinoma-like tumors in patients with von HippelLindau disease are unrelated to sporadic clear cell papillary renal cell carcinoma. Am J Surg Pathol 2013, 37:1131-1139

28. Halat S, Eble JN, Grignon DJ, Lopez-Beltran A, Montironi R, Tan PH, Wang M, Zhang S, MacLennan GT, Cheng L: Multilocular cystic renal cell carcinoma is a subtype of clear cell renal cell carcinoma. Mod Pathol 2010, 23:931-936
29. Weller M, Berger H, Hartmann C, Schramm J, Westphal M, Simon M, Goldbrunner R, Krex D, Steinbach JP, Ostertag CB, Loeffler M, Pietsch T, von Deimling A; German Glioma Network: Combined $1 \mathrm{p} / 19 \mathrm{q}$ loss in oligodendroglial tumors: predictive or prognostic biomarker? Clin Cancer Res 2007, 13:6933-6937

30. Wiens AL, Cheng L, Bertsch EC, Johnson KA, Zhang S, Hattab EM: Polysomy of chromosomes 1 and/or 19 is common and associated with less favorable clinical outcome in oligodendrogliomas: fluorescent in situ hybridization analysis of 84 consecutive cases. J Neuropathol Exp Neurol 2012, 71:618-624

31. Bismar TA, Yoshimoto M, Vollmer RT, Duan Q, Firszt M, Corcos J, Squire JA: PTEN genomic deletion is an early event associated with ERG gene rearrangements in prostate cancer. BJU Int 2011, 107: 477-485

32. Srividya MR, Thota B, Shailaja BC, Arivazhagan A, Thennarasu K, Chandramouli BA, Hegde AS, Santosh V: Homozygous 10q23/PTEN deletion and its impact on outcome in glioblastoma: a prospective translational study on a uniformly treated cohort of adult patients. Neuropathology 2011, 31:376-383

33. Kovacs G, Soudah B, Hoene E: Binucleated cells in a human renal cell carcinoma with 34 chromosomes. Cancer Genet Cytogenet 1988, 31 : $211-215$

34. Furge KA, Lucas KA, Takahashi M, Sugimura J, Kort EJ, Kanayama HO, Kagawa S, Hoekstra P, Curry J, Yang XJ, Teh BT: Robust classification of renal cell carcinoma based on gene expression data and predicted cytogenetic profiles. Cancer Res 2004, 64: $4117-4121$

35. Mackinnon RN, Campbell LJ: The role of dicentric chromosome formation and secondary centromere deletion in the evolution of myeloid malignancy. Genet Res Int 2011, 2011:643628

36. Alexandrov LB, Nik-Zainal S, Wedge DC, Aparicio SA, Behjati S, Biankin AV, et al; Australian Pancreatic Cancer Genome Initiative; ICGC Breast Cancer Consortium; ICGC MMML-Seq Consortium; ICGC PedBrain: Signatures of mutational processes in human cancer. Nature 2013, 500:415-421

37. Davis CF, Ricketts CJ, Wang M, Yang L, Cherniack AD, Shen H, et al; Cancer Genome Atlas Research Network: The somatic genomic landscape of chromophobe renal cell carcinoma. Cancer Cell 2014, 26 : 319-330

38. Kato N, Honma K, Hojo H, Sasou S, Matsuzaki O, Motoyama T: KIT expression in normal and neoplastic renal tissues: immunohistochemical and molecular genetic analysis. Pathol Int 2005, 55:479-483

39. Kruger S, Sotlar K, Kausch I, Horny HP: Expression of KIT (CD117) in renal cell carcinoma and renal oncocytoma. Oncology 2005, 68: 269-275

40. Pan CC, Chen PC, Chiang H: Overexpression of KIT (CD117) in chromophobe renal cell carcinoma and renal oncocytoma. Am J Clin Pathol 2004, 121:878-883 